\title{
Article \\ hPG 80 (Circulating Progastrin), a Novel Blood-Based Biomarker for Detection of Poorly Differentiated Neuroendocrine Carcinoma and Well Differentiated Neuroendocrine Tumors
}

\author{
Aman Chauhan ${ }^{1, *}$, Alexandre Prieur ${ }^{2}$, Jill Kolesar ${ }^{3}{ }^{(0)}$, Susanne Arnold ${ }^{1}$, Léa Payen ${ }^{4}$, Younes Mahi ${ }^{2}$, \\ Berengere Vire $^{2}$, Madison Sands ${ }^{5}\left(\mathbb{C}\right.$, B. Mark Evers ${ }^{6}$, Dominique Joubert ${ }^{2}$ and Lowell Anthony ${ }^{1}(\mathbb{D}$
}

1 Division of Medical Oncology, and the Markey Cancer Center, University of Kentucky, Lexington, KY 40536, USA; susanne.arnold@uky.edu (S.A.); lowell.anthony@uky.edu (L.A.)

2 ECS Progastrin, 1004 Lausanne, Switzerland; a.prieur@ecs-progastrin.com (A.P.); y.mahi@ecs-progastrin.com (Y.M.); b.vire@eurobiodev.com (B.V.); d.joubert@ecs-progastrin.com (D.J.)

3 College of Pharmacy, and the Markey Cancer Center, University of Kentucky, Lexington, KY 40536, USA; jill.kolesar@uky.edu

4 Lyon Sud Hospital, 69310 Pierre-Benite, France; lea.payen-gay@chu-lyon.fr

5 School of Medicine, University of Kentucky, Lexington, KY 40536, USA; madison.sands@uky.edu

6 Department of Surgery, and the Markey Cancer Center, University of Kentucky, Lexington, KY 40536, USA; mark.evers@uky.edu

* Correspondence: amanchauhan@uky.edu

check for updates

Citation: Chauhan, A.; Prieur, A.; Kolesar, J.; Arnold, S.; Payen, L.; Mahi, Y.; Vire, B.; Sands, M.; Evers, B.M.; Joubert, D.; et al. hPG 80 (Circulating Progastrin), a Novel Blood-Based Biomarker for Detection of Poorly Differentiated

Neuroendocrine Carcinoma and Well Differentiated Neuroendocrine

Tumors. Cancers 2022, 14, 863.

https://doi.org/10.3390/

cancers14040863

Academic Editor: Karel Pacak

Received: 7 December 2021

Accepted: 24 December 2021

Published: 9 February 2022

Publisher's Note: MDPI stays neutral with regard to jurisdictional claims in published maps and institutional affiliations.

Copyright: (c) 2022 by the authors. Licensee MDPI, Basel, Switzerland. This article is an open access article distributed under the terms and conditions of the Creative Commons Attribution (CC BY) license (https:// creativecommons.org/licenses/by/ $4.0 /)$.
Simple Summary: Current blood-based biomarkers for neuroendocrine neoplasms (NENs) lack both sensitivity and specificity. Human circulating progastrin $\left(\mathrm{hPG}_{80}\right)$ can be easily measured in plasma by ELISA. This study is the first to examine $\mathrm{hPG}_{80}$ in NENs. The study demonstrated increased levels of $\mathrm{hPG}_{80}$ in all sub-types of NENs, with a high sensitivity and specificity demonstrated. Plasma hPG 80 in NENs may be a diagnostic blood biomarker for both low- and high-grade NENs; further study is warranted. A prospective multi-center trial is ongoing in NET to evaluate $\mathrm{hPG}_{80}$ as a means of monitoring disease (NCT04750954).

Abstract: Current blood-based biomarkers for neuroendocrine neoplasms (NENs) lack both sensitivity and specificity. Human circulating progastrin $\left(\mathrm{hPG}_{80}\right)$ is a novel biomarker that can be easily measured in plasma by ELISA. This study is the first to examine hPG 80 in NENs. Plasma $\mathrm{hPG}_{80}$ was quantified from 95 stage IV NEN patients, using DxPG 80 technology (ECS Progastrin, Switzerland) and compared with $\mathrm{hPG}_{80}$ concentrations in two cohorts of healthy donor controls aged 50-80 $(n=252)$ and 18-25 $(n=137)$. Median $\mathrm{hPG}_{80}$ in NENs patients was $5.54 \mathrm{pM}$ compared to $1.5 \mathrm{pM}$ for the $50-80$ controls and $0.29 \mathrm{pM}$ the $18-25$ cohort $(p<0.0001)$. Subgroup analysis revealed median $\mathrm{hPG}_{80}$ levels significantly higher than for either control cohort in neuroendocrine carcinoma (NEC; $n=25)$ and neuroendocrine tumors (NET; $n=70$ ) including the small-cell lung cancer (SCLC) sub-cohort $(n=13)$. Diagnostic accuracy, estimated by AUCs, was high for NENs, as well as both sub-groups (NEC/NET) when compared to the younger and older control groups. Plasma hPG 80 in NENs may be a diagnostic blood biomarker for both low- and high-grade NENs; further study is warranted. A prospective multi-center trial is ongoing in NET to evaluate $\mathrm{hPG}_{80}$ as a means of monitoring disease (NCT04750954).

Keywords: circulating progastrin; $\mathrm{hPG}_{80}$; blood-based diagnostic biomarker; neuroendocrine neoplasms; neuroendocrine tumors; neuroendocrine carcinoma; small-cell carcinoma

\section{Introduction}

Neuroendocrine neoplasms (NENs) are heterogeneous tumors that originate from various organs and are of variable aggressiveness based on grade and morphology. The incidence of neuroendocrine tumors (NETs) has increased 6.4-fold, making NETs the second 
most prevalent gastrointestinal malignancies after colorectal cancer [1,2]. Currently, no reliable blood-based biomarkers have been identified for NENs. Several biomarkers have been proposed for well-differentiated NETs (e.g., chromogranin A and pancreastatin); however, to date, all of the proposed biomarkers are not particularly sensitive and/or specific [3].

Progastrin, a precursor of gastrin is synthetized by $\mathrm{G}$ cells in gastric antrum and later processed into gastrin [4]. In normal physiologic state, progastrin esnt accumulate in antral G cells, as compared to G34-Gly and fully matured gastrin [5]. Hence, progastrin is not detectable in the blood in normal subjects, barring few exceptions. [6]. In contrast, as a result of GAST gene expression, high $\mathrm{hPG}_{80}$ levels are detected in blood of cancer patients [7-9]. GAST, a target of the B-catenin/Tcf4 pathway, is also found to be activated in many solid tumors [10]. Role of $\mathrm{hPG}_{80}$ in tumorigenesis has been well documented in prior publications $[9,11-14]$. Therefore, we conducted a pilot study to test the presence of $\mathrm{hPG}_{80}$ in neuroendocrine neoplasms.

\section{Materials and Methods}

\subsection{Patients and Control Cohorts}

Institutional Review Board (IRB) approval was secured and banked plasma from patients with high-grade neuroendocrine carcinoma and well-differentiated neuroendocrine tumors was accessed from the University of Kentucky Markey Cancer Center's biospecimen repository.

Control group comprised of plasma samples from two distinct age groups. Plasma from healthy, 137 non fasting (18-25-year-old) blood donors was obtained from the French blood agency (Etablissement Français du Sang) [15]. A second cohort consisted of 50-80year-old; (median 55). Plasma from these 252 fasting subjects was obtained from PROCODE study (NCT03775473, https: / / clinicaltrials.gov/ct2/show / NCT03775473, accessed on 17 December 2021).

\section{2. $h P G_{80}$ Level Measurements in the Blood Samples}

$\mathrm{hPG}_{80}$ was analyzed using ELISA DxPG $80.1 \mathrm{ab}$ kit from ECS-Progastrin. The analytical performances of the kit are described in Cappellini et al. [16]. Limit of Detection (LoD) and the limit of Quantitation (LoQ) is at $1 \mathrm{pM}$ and $3.3 \mathrm{pM}$ respectively. The inter- and intra-assay coefficients of variation (CV\%) is below $10 \%$. No cross-reactivity was detected with gastrin-17, Gastrin-Gly or CTFP (C-Terminus Flanking Peptide). No cross-reactivity was detected with other blood biomarker such as CA125, CEA or PSA. No interference was detected with chemicals such as SN-38, 5-FU or triglycerides, cholesterol, or hemoglobin.

\subsection{Statistical Analysis}

Differences in $\mathrm{hPG}_{80}$ levels were evaluated using Mann-Whitney $U$ tests. The diagnostic discriminative accuracy of $\mathrm{hPG}_{80}$ levels in patients with cancer compared to healthy subjects was assessed using Receiver Operating Characteristics (ROC) curve analysis. Both control groups were used for ROC curve analysis in order to obtain a range of values regarding the diagnosis value of $\mathrm{hPG}_{80}$. Prism software (GraphPad Prism version 9.4 for Windows, GraphPad Software, La Jolla, CA, USA, www.graphpad.com, accessed on 17 December 2021) was used to perform all the statistical analysis and to create figures. The level of significance was set at $p<0.05$.

\section{Results}

\subsection{Diagnostic Performance of $h P G_{80}$ in the Various Cohorts of Cancer Patients}

The demographic characteristics of the neuroendocrine neoplasm (NEN) patients and control cohorts are shown in Table 1. 
Table 1. Clinical and pathological characteristics for NEN, NEC, NET patients, and control cohorts.

\begin{tabular}{|c|c|c|c|c|c|c|}
\hline & & \multirow[t]{2}{*}{ NEN } & \multirow[t]{2}{*}{ NEC } & \multirow[t]{2}{*}{ NET } & \multicolumn{2}{|c|}{ Control Cohorts } \\
\hline & & & & & 18-25 Years Old & 50-80 Years Old \\
\hline & & N (\%) & N (\%) & N (\%) & N (\%) & N (\%) \\
\hline & & $n=95$ & $n=25$ & $n=70$ & $n=137$ & $n=252$ \\
\hline Age (years) & Median (range) & $61(37-86)$ & $61(37-78)$ & $62(37-86)$ & $21(18-25)$ & $55(50-80)$ \\
\hline \multirow{2}{*}{ Gender } & Male & $38(40 \%)$ & $10(40 \%)$ & $28(40 \%)$ & $79(57.7 \%)$ & $99(39.3 \%)$ \\
\hline & Female & $57(60 \%)$ & $15(60 \%)$ & $42(60 \%)$ & $58(42.3 \%)$ & $153(60.7 \%)$ \\
\hline \multirow{2}{*}{$\mathrm{hPG}_{80}$} & Median (IQR), pM & $5.54(0.00-1241)$ & $3.54(1.13-154.1)$ & $5.8(0.00-1241)$ & $<$ LoD & $<$ LoQ \\
\hline & Mean (SD) pM & $28.24(128.8)$ & $20.7(39.96)$ & 30.55 (148.5) & $<\mathrm{LoD}$ & $3.82(0.55)$ \\
\hline \multirow{3}{*}{ Stage } & I to III & $14(14.8 \%)$ & $2(8 \%)$ & $12(17.2 \%)$ & & \\
\hline & IV & $80(84.2 \%)$ & $23(92 \%)$ & $57(81.4 \%)$ & & \\
\hline & Unknown & $1(1.0 \%)$ & $0(0 \%)$ & $1(1.4 \%)$ & & \\
\hline \multirow{8}{*}{ Grade } & \multirow{2}{*}{1} & 33 & 0 & 33 & & \\
\hline & & $(34.7 \%)$ & $(0 \%)$ & $(47.2 \%)$ & & \\
\hline & \multirow{2}{*}{2} & 28 & 0 & 28 & & \\
\hline & & $(29.5 \%)$ & $(0 \%)$ & $(40 \%)$ & & \\
\hline & \multirow{2}{*}{3} & 30 & 25 & 5 & & \\
\hline & & $(31.6 \%)$ & $(100 \%)$ & $(7.1 \%)$ & & \\
\hline & \multirow{2}{*}{ Unknown } & 4 & 0 & 4 & & \\
\hline & & $(4.2 \%)$ & $(0 \%)$ & $(5.7 \%)$ & & \\
\hline \multirow{10}{*}{ Primary Site } & \multirow{2}{*}{ GI tract } & 46 & 4 & 42 & & \\
\hline & & $(48.4 \%)$ & $(16 \%)$ & $(60 \%)$ & & \\
\hline & \multirow{2}{*}{ Pancreas } & 15 & 2 & 13 & & \\
\hline & & $(15.8 \%)$ & $(8 \%)$ & $(18.6 \%)$ & & \\
\hline & \multirow{2}{*}{ SCLC } & 13 & 13 & 0 & & \\
\hline & & $(13.7 \%)$ & $(52 \%)$ & $(0 \%)$ & & \\
\hline & \multirow{2}{*}{ Lung w/o SCLC } & 17 & 4 & 13 & & \\
\hline & & $(17.9 \%)$ & $(16 \%)$ & $(18.6 \%)$ & & \\
\hline & \multirow{2}{*}{ Other } & 4 & 2 & 2 & & \\
\hline & & $(4.2 \%)$ & $(8 \%)$ & $(2.8 \%)$ & & \\
\hline
\end{tabular}

NA: not applicable; LoD: Limit of Detection; LoQ: Limit of Quantification.

The median age of NEN patients was 61 years (37-86 y). Among the 95 NENs, 25 patients (26.3\%) had high-grade neuroendocrine carcinoma (NEC) and 70 patients (73.7\%) were diagnosed with well-differentiated neuroendocrine tumors (NET). The median $\mathrm{hPG}_{80}$ in NENs patients was $5.54 \mathrm{pM}$ (IQR 2.07-17.11 pM) as compared to $1.5 \mathrm{pM}$ (IQR $0.60-3.09 \mathrm{pM}$ ) for patients in the 50-80-year-old control group and $0.29 \mathrm{pM}$ (IQR $0.00-1.27 \mathrm{pM})$ for patients in the 18-25-year-old cohort $(p<0.0001$, two-tailed MannWhitney $U$-test). A subgroup analysis of NENs revealed a median $\mathrm{hPG}_{80}$ of $3.54 \mathrm{pM}$ (IQR $2.02-19.91 \mathrm{pM})$ in neuroendocrine carcinoma (NEC $n=25)$ and $5.8 \mathrm{pM}(\mathrm{IQR} 1.91-16.74 \mathrm{pM})$ in neuroendocrine tumor (NET $n=70$ ). Interestingly, the small-cell lung cancer subcohort $(n=13)$ also showed significant elevation of $\mathrm{hPG}_{80}$ with a median at $9.09 \mathrm{pM}$ (IQR $2.66-25.33 \mathrm{pM})$. All the above-mentioned differences were statistically significant as compared to healthy controls (Figure 1). Table 2 shows the levels of plasma $\mathrm{hPG}_{80}$ in the various study subgroups. 
A.

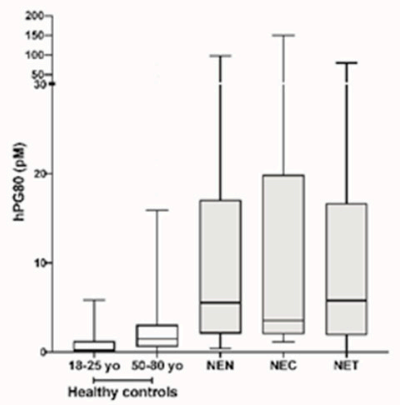

B.

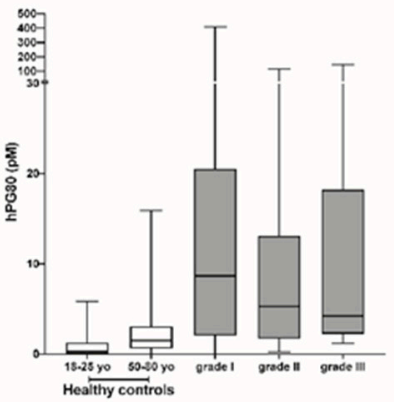

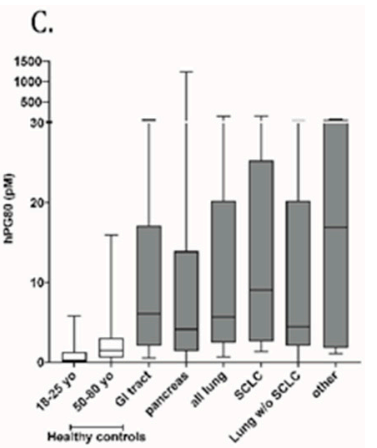

Figure 1. Diagnostic performance of $\mathrm{hPG}_{80}$ in (A) NENs, NEC and NET patient cohorts, (B) by tumor grade, (C) by tumor site as compared to the 18-25-year-old and 50-80-year-old.

Table 2. $\mathrm{hPG}_{80}(\mathrm{pM})$ in plasma from neuroendocrine neoplasm patients depending on the grade and the primary site. Groups are not significantly different from each other.

\begin{tabular}{|c|c|c|c|c|c|c|}
\hline & & \multicolumn{5}{|c|}{ GRADE } \\
\hline & & \multicolumn{2}{|c|}{ Grade I } & Grade II & \multicolumn{2}{|c|}{ Grade III } \\
\hline \multirow{4}{*}{$\mathrm{hPG}_{80}$} & $\begin{array}{c}\text { Median } \\
\text { (range), pM }\end{array}$ & \multicolumn{2}{|c|}{$8.66(0.00-1241)$} & $5.3(0.00-142.1)$ & \multicolumn{2}{|c|}{$4.22(1.13-154.1)$} \\
\hline & $\begin{array}{c}\text { Mean (SD), } \\
\text { pM }\end{array}$ & \multicolumn{2}{|c|}{$48.71(214.4)$} & $16.37(32.1)$ & \multicolumn{2}{|c|}{$19.18(36.77)$} \\
\hline & & \multicolumn{5}{|c|}{ PRIMARY SITE } \\
\hline & & GI Tract & Pancreas & SCLC & Lung not SCLC & Other \\
\hline \multirow{2}{*}{$\mathrm{hPG}_{80}$} & $\begin{array}{c}\text { Median } \\
\text { (range), pM }\end{array}$ & $\begin{array}{c}6.06 \\
(0.00-142.1)\end{array}$ & $4.14(0.00-1241)$ & $\begin{array}{c}9.09 \\
(1.35-124.1)\end{array}$ & $4.51(0.00-34.85)$ & $\begin{array}{c}16.89 \\
(1.13-86.87)\end{array}$ \\
\hline & $\begin{array}{c}\text { Mean (SD), } \\
\text { pM }\end{array}$ & $\begin{array}{c}13.88 \\
(24.02)\end{array}$ & 88.9 (318.9) & $\begin{array}{c}30.36 \\
(52.78)\end{array}$ & 11.37 (11.35) & $\begin{array}{c}30.45 \\
(39.78)\end{array}$ \\
\hline
\end{tabular}

$\mathrm{hPG}_{80}$ : circulating progastrin; IQR: interquartile range; pM: picomolar; SD: standard deviation; GI: gastrointestinal; SCLC: small-cell lung cancer.

\subsection{Diagnostic Performance of $h P G_{80}$ in Each Sub-Cohort of Cancer Type}

As shown in Figure 2, diagnostic accuracy, estimated by the ROC AUCs, is 0.89 for all NENs, 0.87 for NETs, and 0.92 for NECs when compared to the young 18-25 y control group; for the older $50-80$ y cohort, the values were 0.75 for all NENs, 0.74 for NETs, and 0.75 for NECs.

As shown in Figure 3, diagnostic performances of $\mathrm{hPG}_{80}$ were tested using $90 \%$ specificity (CI: $89.8 \%$ to $93.4 \%$ for the $18-25$-year-old and $84.4 \%$ to $93.3 \%$ for the $50-80$-yearold control groups) for all sub-cohorts. The sensitivity ranged from $58.67 \%$ (CI: $40.74 \%$ to $74.49 \%$ ) for lung other than SCLC to $69.23 \%$ (CI: $42.37 \%$ to $87.32 \%$ ) for SCLC, when compared to the $18-25$ y control group. The sensitivity ranged from $37.50 \%$ (CI: $21.16 \%$ to $57.29 \%$ ) for NEC to $53.85 \%$ (CI: $29.14 \%$ to $76.79 \%$ ) for SCLC, when compared to the $50-80 \mathrm{y}$ control group. 
A.

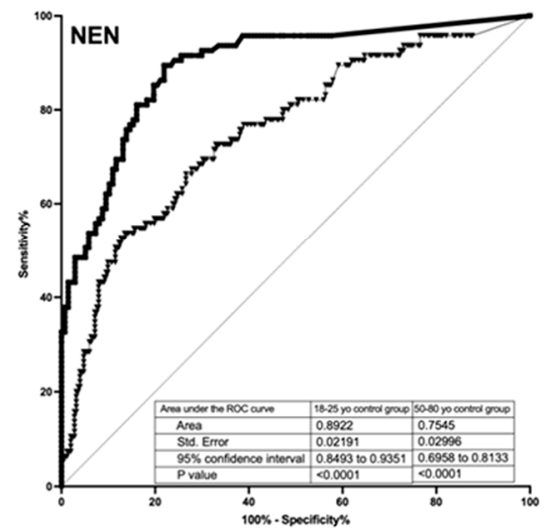

B.

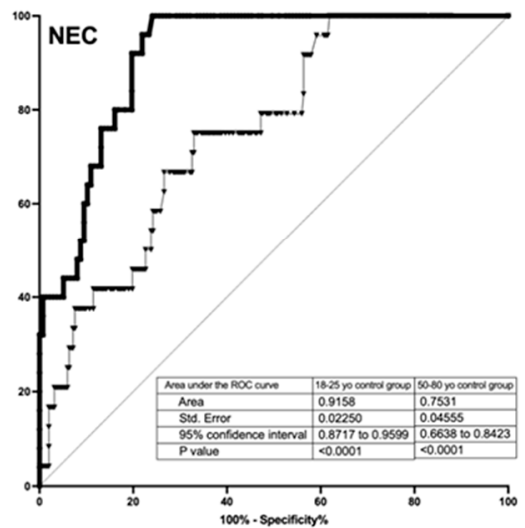

C.

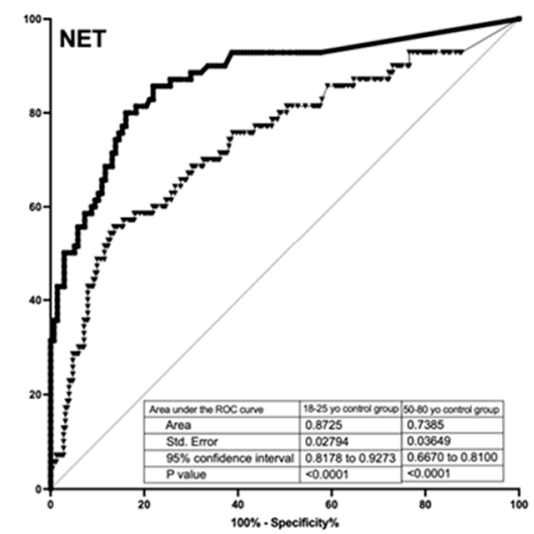

Figure 2. Diagnostic accuracy, estimated by the Receiver Operator Characteristic (ROC) Area Under the Curve (AUC)s, is 0.89 for all NENs (A), 0.92 for NECs (B), and 0.87 for NETs (C) when compared to the young 18-25 y control group (square); for the older 50-80 y cohort, the values were 0.75 for all NENs (A), 0.75 for NECs (B), and 0.74 for NETs (C) (triangles).

A.

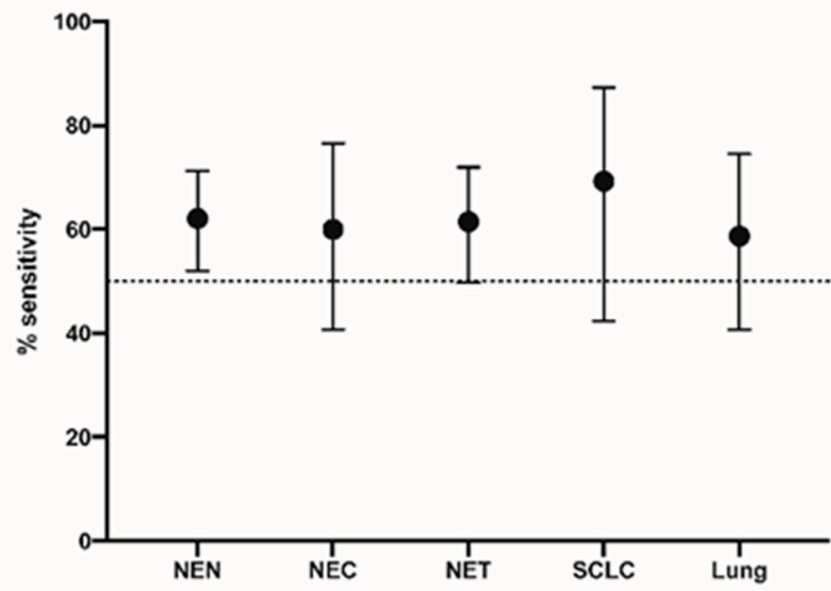

\begin{tabular}{|l|r|r|r|}
\hline & \multicolumn{3}{|c|}{ 18-25 yo } \\
\hline & \multicolumn{1}{|c|}{ Mean } & Upper Limit & Lower Limit \\
\hline NEN & 62.11 & 71.21 & 52.06 \\
\hline NEC & 60.00 & 76.60 & 40.74 \\
\hline NET & 61.43 & 71.95 & 49.72 \\
\hline SCLC & 69.23 & 87.32 & 42.37 \\
\hline Lung & 58.67 & 74.49 & 40.74 \\
\hline
\end{tabular}

B.

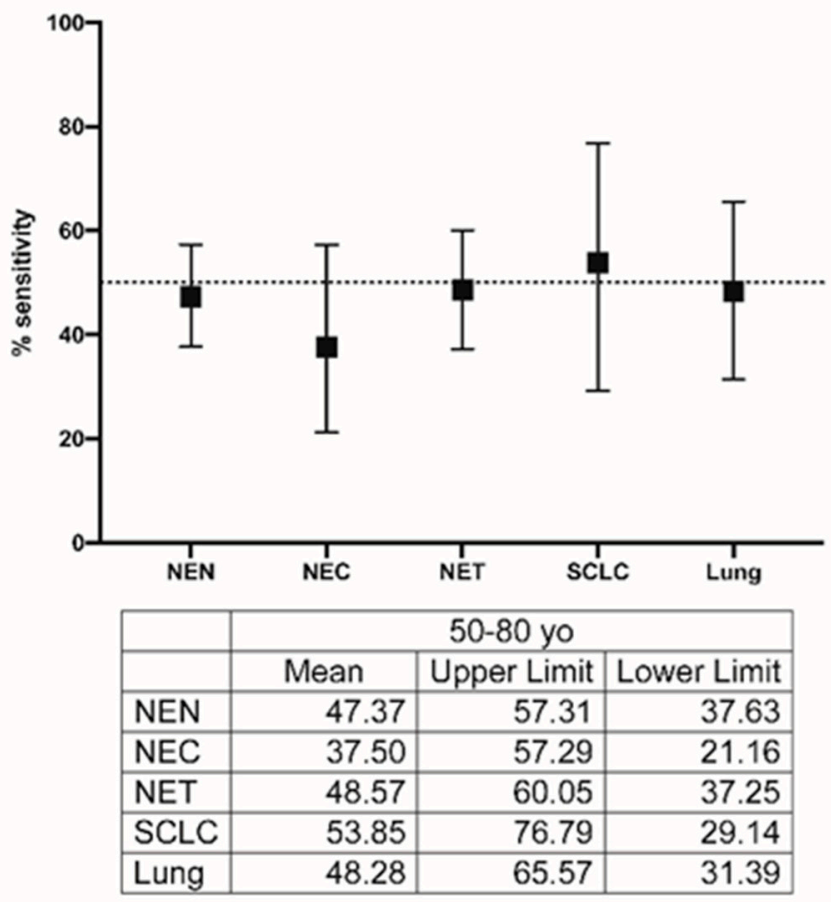

Figure 3. Sensitivity of $\mathrm{hPG}_{80}$ in the all-patient (neuroendocrine neoplasm) cohorts with a specificity set at $90 \%$ as compared to (A) 18-25 y control group and (B) 50-80 y control group.

\section{Discussion}

Neuroendocrine neoplasms represent a group of diseases with a common neuroendocrine lineage however each subgroup maintains its unique morphology, molecular biology, and phenotype. WHO now clearly distinguishes poorly differentiated neuroendocrine carcinoma aka NEC from well differentiated neuroendocrine tumor, also known as NET. NEC is characterized by an aggressive clinical course, is distinctively poorly differentiated, displays large cell or small cell morphology, and has a molecular profile indicative of mutation in TP53 and loss of RB1. In contrast, the well differentiated NETs are relatively indolent and can be differentiated into grade 1, 2, and 3 based on Ki 67 index. It is critical to distinguish between NET and NEC as both can have a variable clinical 
course and management paradigms [17]. However, a common unifying factor for both NET and NEC is lack of reliable blood-based diagnostic biomarker. hPG $_{80}$ (human circulating progastrin) is a pan tumor biomarker that has been found to be over-expressed in multiple malignancies. $\mathrm{hPG}_{80}$ synthesis is product of overexpression of GAST gene in cancer cells and human circulating progastrin can now be measured accurately with help of DxPG 80 Enzyme-Linked Immunosorbent Assay (ELISA) based test [8,16].

In this study, we investigated the diagnostic value of plasma $\mathrm{hPG}_{80}$ in patients with both low- and high-grade NENs. Our data revealed that plasma hPG 80 levels in 95 patients with NENs was significantly higher compared to healthy blood donors. NENs are a heterogenous group of diseases that can arise from any location in the body [18]. Because of its broad expression in all types of NENs, plasma $\mathrm{hPG}_{80}$ could represent a novel biomarker to diagnose NENs. In fact, except chromogranin A (CgA), which is secreted by most NENs, currently-used biomarkers (neuron-specific enolase, pancreatic peptide and 5-hydroxyindoleacetic acid) have restricted expression, thus limiting their diagnostic value [19]. We showed that $\mathrm{hPG}_{80}$ diagnostic sensitivity ranged from $58.67 \%$ to $69.23 \%$ with a $90 \%$ specificity in NENs. Only few biomarkers including CgA are currently used in the diagnosis of patients with NENs [20]. Although these biomarkers are considered useful to aid diagnosis, they display limited sensitivity and specificity. Indeed, the sensitivity and specificity of CgA ranges between 43 and 100\%, and below 50\%, respectively [3]. In addition, elevated $\mathrm{CgA}$ levels are also found in many other conditions such as renal and hepatic failure, inflammatory diseases, or following the use of proton-pump inhibitors [21]. Another limitation to the use of CgA for NENs diagnosis comes from the absence of direct involvement in the mechanisms that underlie tumorigenic process including cell proliferation, migration, invasion, and metastasis [22]. By contrast, numerous studies have demonstrated that $\mathrm{hPG} 80$ contribute to tumorigenesis and tumor development [9,11-13]. Plasma $\mathrm{hPG}_{80}$ levels correlate with tumor burden but also with tumor activity. Indeed, $\mathrm{hPG}_{80}$ level significantly decreases upon surgery in peritoneal carinomatosis and upon remission in hepatocellular cancer [8]. In addition, in hepatocellular cancer, the $\mathrm{hPG}_{80}$ level correlates with response to treatment and disease progression [8]. Last but not least, we have recently shown that $\mathrm{hPG}_{80}$ could be used for prognosticating survival in metastatic renal cell carcinoma [7]. In line with these data and to gain further insight into its potential utility as a biomarker in NENs, the role of $\mathrm{hPG}_{80}$ in disease monitoring is being studied in an NCI (National Cancer Institute) sponsored multi center NET clinical trial (ETCTN 10450). Plasma $\mathrm{hPG}_{80}$ will be serially collected at baseline, at each radiographic (CT/MRI) assessment, and at the time of progression.

Recently, the NETest, a blood-derived multianalyte test that measures the expression of 51 circulating mRNA in blood, has been shown to outperform CgA in the diagnosis of NENs [23]. NETest diagnostic accuracy, sensitivity, and specificity, were 97, 99, and 95\%, respectively [23]. However widespread use of this biomarker may be limited [24].

Due to the rarity of NECs, most of the molecular studies have focused on NETs. They demonstrated that signaling pathways such as PI3K-Akt, Ras/Raf/MEK/ERK, Notch, and $W n t / \beta$-catenin signaling contribute to NET pathogenesis [10]. The Wnt-signaling pathway is essential to regulate cell proliferation, migration during embryogenesis, and tumorigenesis in various cancers [25]. Gene mutations in well-known components of the Wnt-signaling pathways, such as $\beta$-catenin and $A P C$, and repression of Wnt inhibitor genes by DNA methylation or histone modification of their promoters (SFRP-1, Axin-2, $D K K-1, D K K-3$, and WIF-1) are frequently observed in NET cell lines and human NET tumor samples [10]. In addition, analysis of somatic mutations across 21 types of NETs revealed that the gene $M E N 1$, encoding a negative regulator of $\beta$-catenin, was the most commonly mutated gene in NETs (8 out of 21 NET types) [26,27]. Remarkably the gene GAST, encoding progastrin, is a direct target of the Wnt oncogenic pathway [28]. Therefore, we can hypothesize that abnormal expression of the Wnt signaling pathway in NENs could be linked to the overexpression of $\mathrm{hPG}_{80}$ in these tumors. 
Our study presents some limitations starting with the retrospective nature of the study and the low patient number, especially in the different subgroups analyzed. Second, most of the patients ( $84 \%$ ) have advanced disease (stage IV), not allowing for evaluation of the diagnostic value of $\mathrm{hPG}_{80}$ in early-stage patients. Lastly, the current study does not account for potential confounders like use of proton-pump inhibitors, or fasting vs. post-prandial state. We acknowledge that PPI usage could induce gastrin hyper secretion (hypergastrinemia); however, to our knowledge, there is no publication showing an increase in $\mathrm{hPG}_{80}$ during PPI usage. Furthermore, as described in Cappellini [16], we would like to mention that the kit $\left(\mathrm{DxPG}_{80}\right)$ that was used to measure $\mathrm{hPG}_{80}$ (human circulating progastrin) does not recognize any other forms of gastrin peptides, avoiding any risk of false positivity due to PPI usage and hypergastrinemia. Nonetheless, we are currently setting up a clinical study to answer this very question. Finally, a large prospective study, including more cases with early-stage disease, should strengthens the significance of using $\mathrm{hPG}_{80}$ as a new diagnostic biomarker in NENs.

\title{
5. Conclusions
}

This first-ever study of plasma $\mathrm{hPG}_{80}$ in NENs confirms that $\mathrm{hPG}_{80}$ is elevated in both low- and high-grade NENs, and suggests that $\mathrm{hPG}_{80}$ could be considered as a potential diagnostic blood-based biomarker for NENs diagnosis.

\begin{abstract}
Author Contributions: A.C.: conceptualization, methodology, investigation, data curation, data analysis, original draft preparation, writing and review; A.P.: investigation, methodology, data curation, data analysis, writing and review; J.K.: investigation, data curation, data analysis, writing and review; S.A.: investigation, data curation, data analysis, writing and review; L.P.: investigation, data curation, data analysis, writing and review; Y.M.: investigation, data curation, data analysis, writing and review; B.V.: investigation, data curation, data analysis, writing and review; M.S.: investigation, data curation, data analysis, writing and review; B.M.E.: investigation, data curation, data analysis, writing and review; D.J.: investigation, data curation, data analysis, writing and review; L.A.: investigation, data curation, data analysis, writing and review. All authors read and approved the final manuscript.
\end{abstract}

Funding: This research was supported by the BPTP Shared Resource of the University of Kentucky Markey Cancer Center (P30 CA177558) and ECS Progastrin.

Institutional Review Board Statement: The study was conducted according to the guidelines of the Declaration of Helsinki, and the protocol was approved by the Markey Cancer Center Institutional Review Board (IRB) Number: 50940, approved 4/21/2020.

Informed Consent Statement: Informed consent was not required.

Data Availability Statement: All data generated or analyzed during this study are included in this published article. Individual deidentified patient data can be shared upon request and IRB approval.

Acknowledgments: UK Markey Cancer Center's Research Communications Office assisted with preparation of this manuscript.

Conflicts of Interest: The employees of ECS Progastrin are A.P., Y.M., B.V. and D.J. Those with no competing interest are J.K., S.A., L.P., M.S., B.M.E. and L.A.

\section{References}

1. Chauhan, A.; Kohn, E.; Del Rivero, J. Neuroendocrine Tumors-Less Well Known, Often Misunderstood, and Rapidly Growing in Incidence. JAMA Oncol. 2020, 6, 21-22. [CrossRef] [PubMed]

2. Dasari, A.; Shen, C.; Halperin, D.; Zhao, B.; Zhou, S.; Xu, Y.; Shih, T.; Yao, J.C. Trends in the Incidence, Prevalence, and Survival Outcomes in Patients with Neuroendocrine Tumors in the United States. JAMA Oncol. 2017, 3, 1335-1342. [CrossRef] [PubMed]

3. Oberg, K.; Modlin, I.M.; De Herder, W.; Pavel, M.; Klimstra, D.; Frilling, A.; Metz, D.C.; Heaney, A.; Kwekkeboom, D.; Strosberg, J.; et al. Consensus on biomarkers for neuroendocrine tumour disease. Lancet Oncol. 2015, 16, e435-e446. [CrossRef]

4. $\quad$ Rehfeld, J.F.; Zhu, X.; Norrbom, C.; Bundgaard, J.R.; Johnsen, A.H.; Nielsen, J.E.; Vikesaa, J.; Stein, J.; Dey, A.; Steiner, D.F.; et al. Prohormone convertases $1 / 3$ and 2 together orchestrate the site-specific cleavages of progastrin to release gastrin-34 and gastrin-17. Biochem. J. 2008, 415, 35-43. [CrossRef] 
5. Varro, A.; Voronina, S.; Dockray, G.J. Pathways of processing of the gastrin precursor in rat antral mucosa. J. Clin. Investig. 1995, 95, 1642-1649. [CrossRef] [PubMed]

6. Siddheshwar, R.K.; Gray, J.C.; Kelly, S.B. Plasma levels of progastrin but not amidated gastrin or glycine extended gastrin are elevated in patients with colorectal carcinoma. Gut 2001, 48, 47-52. [CrossRef]

7. Kohli, M.; Tan, W.; Vire, B.; Liaud, P.; Blairvacq, M.; Berthier, F.; Rouison, D.; Garnier, G.; Payen, L.; Cousin, T.; et al. Prognostic Value of Plasma hPG 80 (Circulating Progastrin) in Metastatic Renal Cell Carcinoma. Cancers 2021, 13, 375. [CrossRef] [PubMed]

8. You, B.; Mercier, F.; Assenat, E.; Langlois-Jacques, C.; Glehen, O.; Soule, J.; Payen, L.; Kepenekian, V.; Dupuy, M.; Belouin, F.; et al. The oncogenic and druggable $\mathrm{hPG}_{80}$ (Progastrin) is overexpressed in multiple cancers and detected in the blood of patients. EBioMedicine 2019, 51, 102574. [CrossRef] [PubMed]

9. Prieur, A.; Cappellini, M.; Habif, G.; Lefranc, M.P.; Mazard, T.; Morency, E.; Pascussi, J.M.; Flaceliere, M.; Cahuzac, N.; Vire, B.; et al. Targeting the Wnt Pathway and Cancer Stem Cells with Anti-progastrin Humanized Antibodies as a Potential Treatment for K-RAS-Mutated Colorectal Cancer. Clin. Cancer Res. 2017, 23, 5267-5280. [CrossRef]

10. Kim, J.T.; Li, J.; Jang, E.R.; Gulhati, P.; Rychahou, P.G.; Napier, D.L.; Wang, C.; Weiss, H.L.; Lee, E.Y.; Anthony, L.; et al. Deregulation of Wnt/beta-catenin signaling through genetic or epigenetic alterations in human neuroendocrine tumors. Carcinogenesis 2013, 34 953-961. [CrossRef]

11. Giraud, J.; Failla, L.M.; Pascussi, J.M.; Lagerqvist, E.L.; Ollier, J.; Finetti, P.; Bertucci, F.; Ya, C.; Gasmi, I.; Bourgaux, J.F.; et al Autocrine Secretion of Progastrin Promotes the Survival and Self-Renewal of Colon Cancer Stem-like Cells. Cancer Res. 2016, 76, 3618-3628. [CrossRef] [PubMed]

12. Hollande, F.; Lee, D.J.; Choquet, A.; Roche, S.; Baldwin, G.S. Adherens junctions and tight junctions are regulated via different pathways by progastrin in epithelial cells. J. Cell Sci. 2003, 116, 1187-1197. [CrossRef] [PubMed]

13. Pannequin, J.; Delaunay, N.; Buchert, M.; Surrel, F.; Bourgaux, J.F.; Ryan, J.; Boireau, S.; Coelho, J.; Pélegrin, A.; Singh, P.; et al. $\beta$-Catenin/Tcf-4 Inhibition after Progastrin Targeting Reduces Growth and Drives Differentiation of Intestinal Tumors. Gastroenterology 2007, 133, 1554-1568. [CrossRef]

14. Singh, P.; Owlia, A.; Varro, A.; Dai, B.; Rajaraman, S.; Wood, T. Gastrin gene expression is required for the proliferation and tumorigenicity of human colon cancer cells. Cancer Res. 1996, 56, 4111-4115.

15. White, M.C.; Holman, D.M.; Boehm, J.E.; Peipins, L.A.; Grossman, M.; Henley, S.J. Age and cancer risk: A potentially modifiable relationship. Am. J. Prev. Med. 2014, 46, S7-S15. [CrossRef] [PubMed]

16. Cappellini, M.; Flaceliere, M.; Saywell, V.; Soule, J.; Blanc, E.; Belouin, F.; Ortiz, E.; Canterel-Thouennon, L.; Poupeau, S.; Tigrett, S.; et al. A novel method to detect hPG 80 (human circulating progastrin) in the blood. Anal. Methods 2021, 13, 4468-4477. [CrossRef] [PubMed]

17. Rindi, G.; Klimstra, D.S.; Abedi-Ardekani, B.; Asa, S.L.; Bosman, F.T.; Brambilla, E.; Busam, K.J.; de Krijger, R.R.; Dietel, M.; El-Naggar, A.K.; et al. A common classification framework for neuroendocrine neoplasms: An International Agency for Research on Cancer (IARC) and World Health Organization (WHO) expert consensus proposal. Mod. Pathol. 2018, 31, 1770-1786. [CrossRef] [PubMed]

18. Oronsky, B.; Ma, P.C.; Morgensztern, D.; Carter, C.A. Nothing But NET: A Review of Neuroendocrine Tumors and Carcinomas. Neoplasia 2017, 19, 991-1002. [CrossRef]

19. Herrera-Martinez, A.D.; Hofland, L.J.; Galvez Moreno, M.A.; Castano, J.P.; de Herder, W.W.; Feelders, R.A. Neuroendocrine neoplasms: Current and potential diagnostic, predictive and prognostic markers. Endocr. Relat. Cancer 2019, 26, R157-R179. [CrossRef]

20. Ahmed, M. Gastrointestinal neuroendocrine tumors in 2020. World J. Gastrointest. Oncol. 2020, 12, 791-807. [CrossRef]

21. Modlin, I.M.; Gustafsson, B.I.; Moss, S.F.; Pavel, M.; Tsolakis, A.V.; Kidd, M. Chromogranin A-Biological function and clinical utility in neuro endocrine tumor disease. Ann. Surg. Oncol. 2010, 17, 2427-2443. [CrossRef] [PubMed]

22. Walenkamp, A.; Crespo, G.; Fierro Maya, F.; Fossmark, R.; Igaz, P.; Rinke, A.; Tamagno, G.; Vitale, G.; Oberg, K.; Meyer, T Hallmarks of gastrointestinal neuroendocrine tumours: Implications for treatment. Endocr. Relat. Cancer 2014, 21, R445-R460. [CrossRef] [PubMed]

23. Malczewska, A.; Kos-Kudla, B.; Kidd, M.; Drozdov, I.; Bodei, L.; Matar, S.; Oberg, K.; Modlin, I.M. The clinical applications of a multigene liquid biopsy (NETest) in neuroendocrine tumors. Adv. Med. Sci. 2020, 65, 18-29. [CrossRef] [PubMed]

24. Ma, Z.Y.; Gong, Y.F.; Zhuang, H.K.; Zhou, Z.X.; Huang, S.Z.; Zou, Y.P.; Huang, B.W.; Sun, Z.H.; Zhang, C.Z.; Tang, Y.Q.; et al. Pancreatic neuroendocrine tumors: A review of serum biomarkers, staging, and management. World J. Gastroenterol. 2020, 26, 2305-2322. [CrossRef] [PubMed]

25. Nusse, R.; Clevers, H. Wnt/beta-Catenin Signaling, Disease, and Emerging Therapeutic Modalities. Cell 2017, 169, 985-999. [CrossRef] [PubMed]

26. Jiang, X.; Cao, Y.; Li, F.; Su, Y.; Li, Y.; Peng, Y.; Cheng, Y.; Zhang, C.; Wang, W.; Ning, G. Targeting beta-catenin signaling for therapeutic intervention in MEN1-deficient pancreatic neuroendocrine tumours. Nat. Commun. 2014, 5, 5809. [CrossRef]

27. Cao, Y.; Zhou, W.; Li, L.; Wang, J.; Gao, Z.; Jiang, Y.; Jiang, X.; Shan, A.; Bailey, M.H.; Huang, K.L.; et al. Pan-cancer analysis of somatic mutations across 21 neuroendocrine tumor types. Cell Res. 2018, 28, 601-604. [CrossRef]

28. Koh, T.J.; Chen, D. Gastrin as a growth factor in the gastrointestinal tract. Regul. Pept. 2000, 93, 37-44. [CrossRef] 